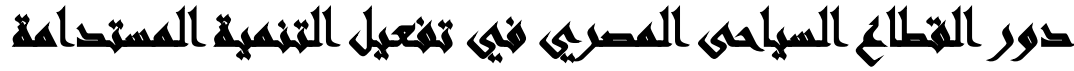

\section{[17]}

\author{
عبير فرحات(') - كريم مصطفى جوهر (')- محمد محمود حسانين(r) - دعاء محمود علي

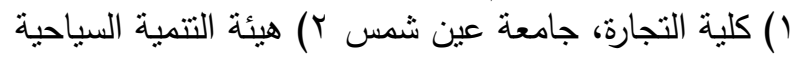

\section{المستون}

يهدف البحث الى دراسة السياحة والتتمية المستدامة ومدى تأثنرها على القطاعات

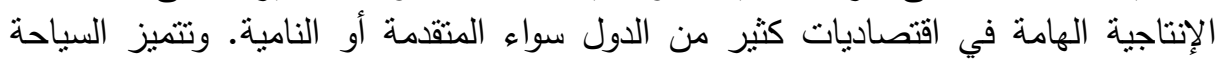

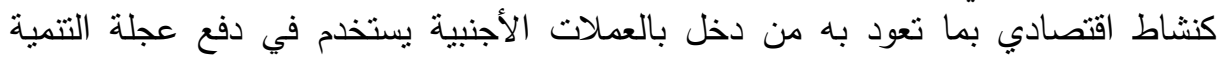
بالدولة. والتعرف على معوقات ومحددات النشاط السياحي في مصر وكيفية دعمه والتعرف

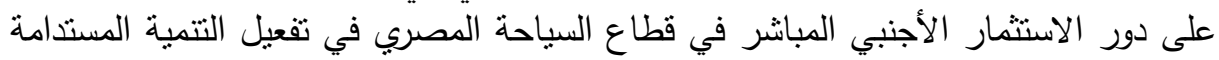

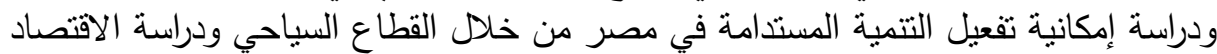
الاخضر ومدى تحقيقة فى مصر وتحقيق نوعية حياة أفضل للسكان والحفاظ علئ علي البيئة واحترامها وترشيد الاستخدام العقلاني للموارد وتعزيز وعي السكان بالمشكلات البيائية القائية الئمة

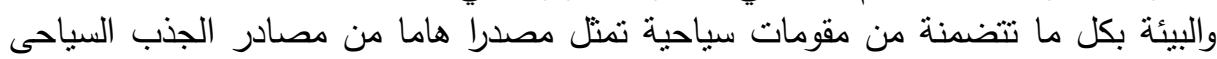

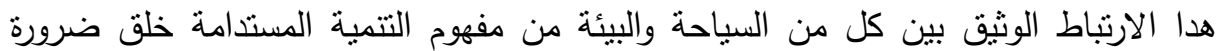
لوضع معايير للاستخدام الأمتل لهذه الموارد دون إحداث الحاث تأثنيرات سلبية عليها.

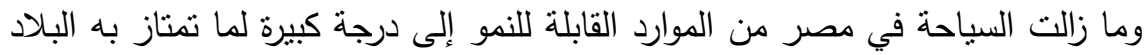

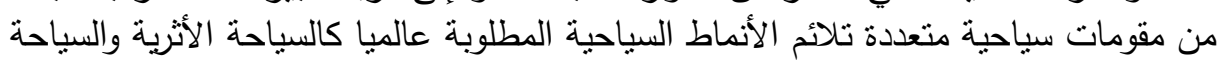

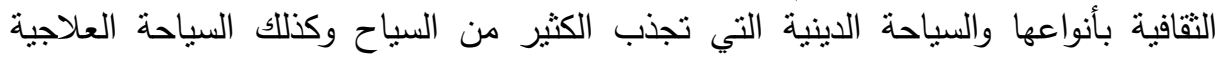

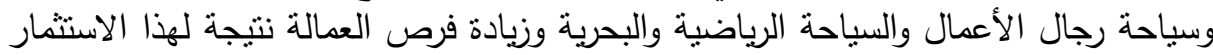

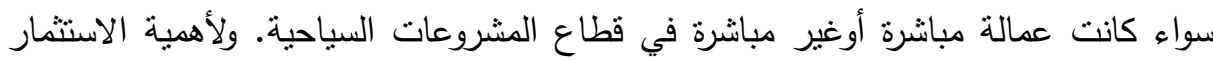

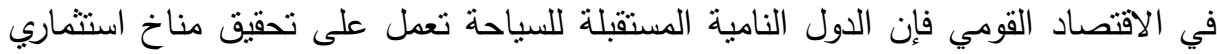
مستقر سواء بالنسبة للاستتمارات الوطنية أوالأجنبية وتتمثل المشكلات البيئية عوامل طانية لاردان

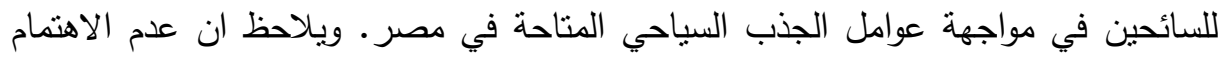

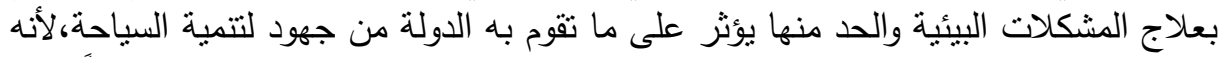

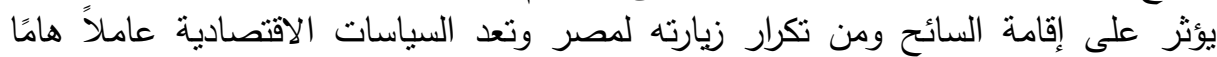

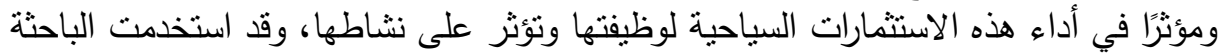

المنهج التحليلى.

$$
\text { المجلد الحادي والأربعون، الجزء الثالث، مارس 11 إ. }
$$


وتتبر النتائج إلى أن التحرك نحو الاقتصاد الاخضر لدية القدرة على تحقيق التتمية

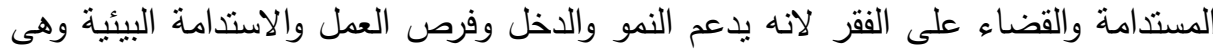
صناعة مستديمة لا تضر بالبيئة الطبيعية وهى أداه لتحقيق أهداف التتمية المستدامة للسياحة.

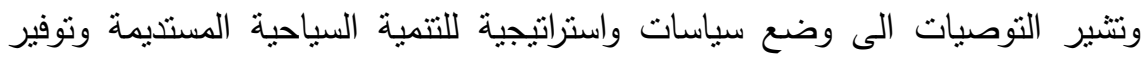

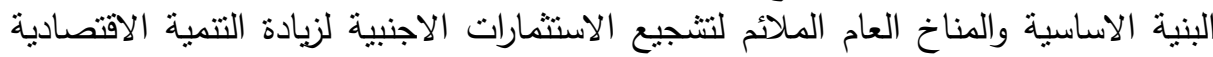
وبالتالى التتمية المستدامة مع الحفاظ على البيئة من الثلوث. الأثاث

\section{المجنهـ}

السياحة علم وصناعة وهى من القطاعات الإنتاجية الهامة في اقتصاديات كثير من

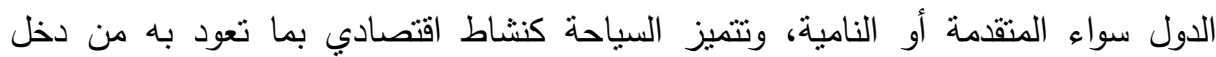
بالعملات الأجنبية بستخدم في دفع عجلة التتمية بالدولة. وما زالت السياحة في مصر من الموارد القابلة للنمو إلى درجة كبيرة لما تمتاز بة البلاد من مقومات سياحية متعددة تلائم الأنماط السياحية المطلوبة عالميا كالسياحة الأثرية والسباحة الثقافية بأنواعها والسياحة الدينية التي تجذب الكثير من السياح وكذلك السياحة العلاجية وسياحة رجال الأعمال والسياحة الرياضية والبحرية.

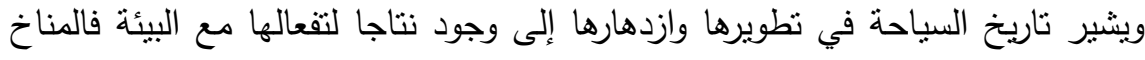
المتندل وتضاريس الأرض ذات الجاذبية السياحية من جبال وبحيرات وصحراء وشواطئ وينابيع من أهم المعالم التي ساعدت على اتساع قاعدة السياحة كأحد أسباب الراحة النفسية والبدنية للإنسان.

وقد بدأ خبراء السياحة وعلماؤها في الآونة الأخيرة بالاهنمام بالأثر المنبادل بين السياحة

$$
\begin{aligned}
& \text { والبيئة ، وتتكون البيئة من ثناث منظومات هي: } \\
& \text { - الأنظمة السياسية. } \\
& \text { - - الأنظمة الاقتصادية. } \\
& \text { - الأنظمة الاجتماعية. }
\end{aligned}
$$


وحيث أن قطاع السياحة من أكثر قطاعات الاقتصاد القومي المصري حساسية إزاء

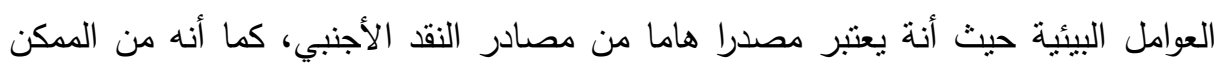

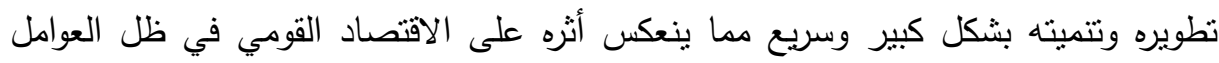

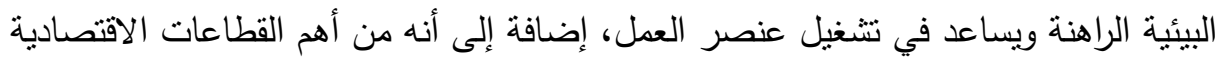
الواعدة.

ويجدر بنا هنا أن نذكر أن القطاع السياحي يعد أحد أهم القطاعات الجاذبة للاستثمار

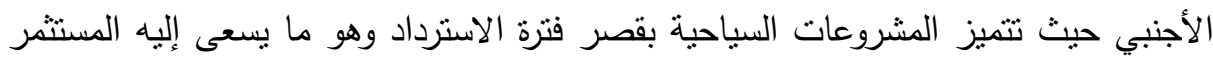
الأجنبي. (ف. دوجلاس مموشيست، مبادئ التتمية المستدامة، . . . ب).

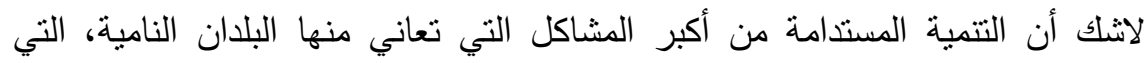

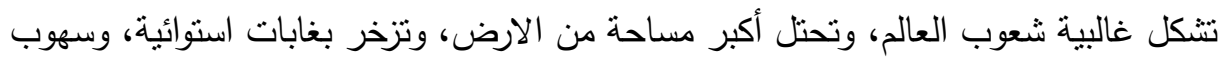

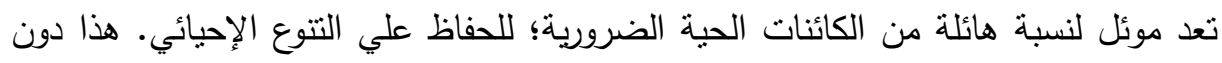
الحديث عن مواردها الطبيعية. وعلي اعتبار أن الاستدامة نتاج لعمل إنساني في المقام الأول،

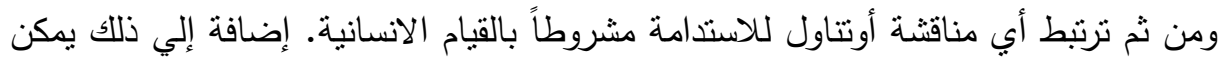

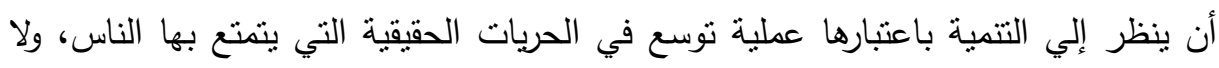
ريب في أن النظرة إلي التتمية في ضوء توسع الحريات الموضوعية من شأنه أن يوجها

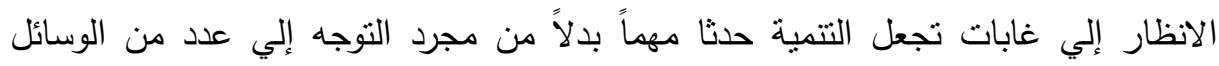

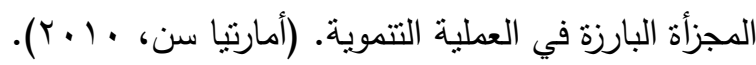

\section{xalyad}

تمنل المشكلات البيئية عوامل طارده للسائحين في مواجهة عوامل الجذب السياحي المتاحة في مصر ، ويلاحظ أن:

عدم الاهتمام بعلاج المشكلات البيئية والحد منها يؤثر على ما تقوم به الدولة من جهود للتمبة السياحة، لأنه يؤثز على إقامة السائح ومن تكرار زيارته لمصر ، وتعد السياسات

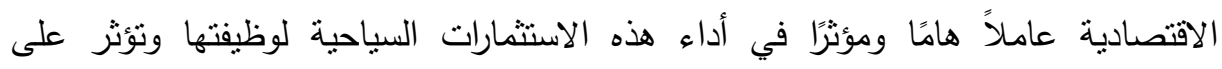


نشاطها. (أحمد عبد السلام السيد رمضان، ورقة عمل عن المشاكل والصعوبات التي تواجه

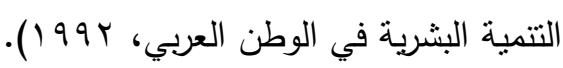

ومن ثم تتركز مشكلة البحث حول مدى وجود تطبيق فعلي وجاد للتنمية المستدامة والحفاظ على البيئة من خلال تطبيق المعايير البيئية اللازمة في السياحة المصرية، ودئة ودراسة

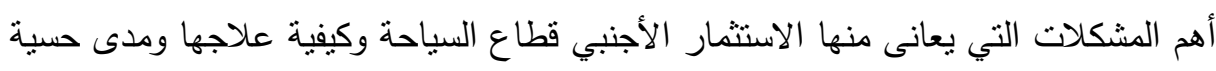

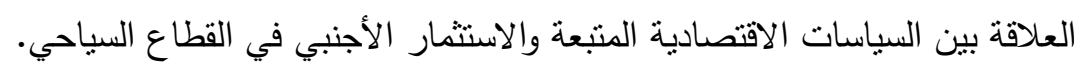
المعايير البيئية تكون من ضمن خطة المشروعات والسياسات الاقتصادية وهي في

التمركز في المدن الكبرى وضعف شديد عند ملاحظة نواجها في الريف حوالي (•v\%)

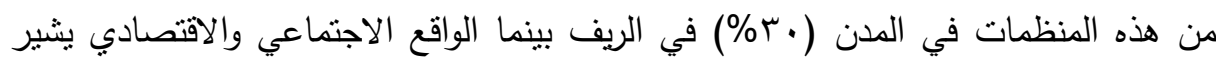

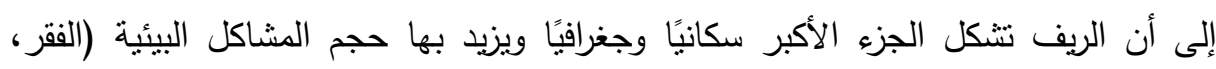

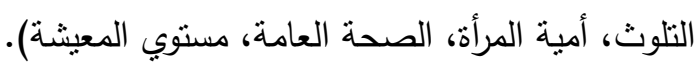

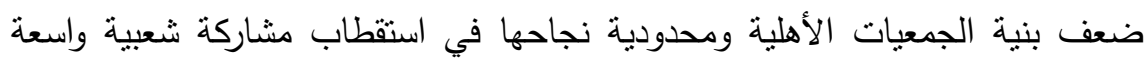
وغياب آليات العمل الديمقراطي داخل هذه المنظمات ويمكن التعيين عن هذه السلبيات في

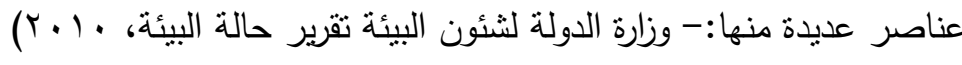

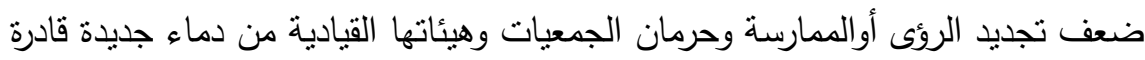

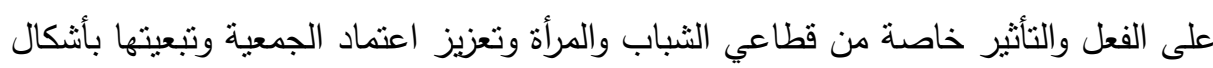
مختلفة وغياب المساءلة والثفافية. سيطرة البعد الخيري على هذه المنظمات القائمة على المساعدة المالية والعينية مع إغفال كبير للبعد التتموي ومن أسباب ذللك "اتساع رقعة الفقر نزايد الحروب الداخلية والإقليمية

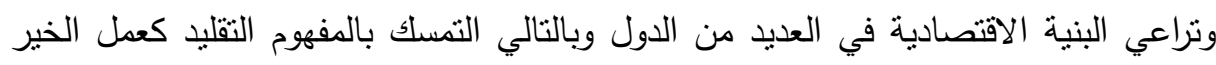


تتمحور خدمات المنظمات العاملة في قطاع الخدمات الاجتماعية حول رعاية الأطفال

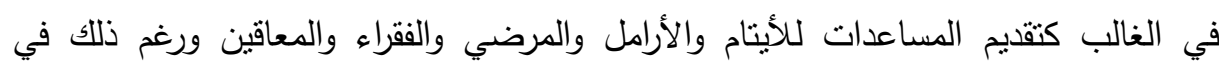

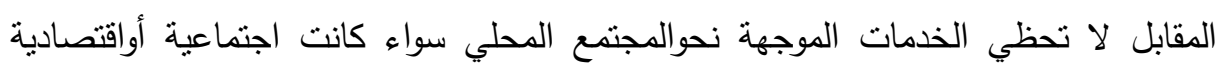

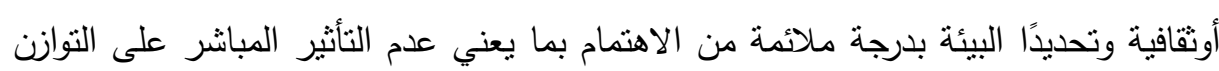

لم تتمكن هذه المنظمات من تحقيق الاستقلالية المطلوبة عن المؤسسات الحكومية

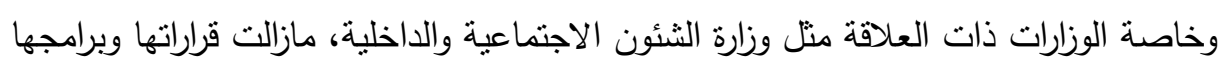
وسياساتها العامة تخضع لتأثير الحكومة وتسعي إلى مباركتها. (وزارة الدولة لشئون البيئة تقرير حالة البيئة، • ( • (Y).

\section{المشكلات التي تعوق الاستثمارات السياحية:}

1-عدم وجود تخطيط واضح المعالم يبني خريطة مصر السياحية يقتصر عمل وزارة السياحة

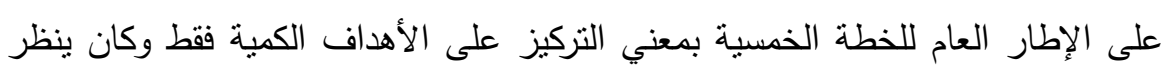

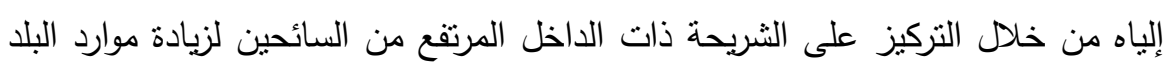
من النقد الأجنبي وكانت هناك نظرة أخرى وهي التركيز على النمط السباحي ذوالعائد المرتفع منل سياحة المؤتمرات.

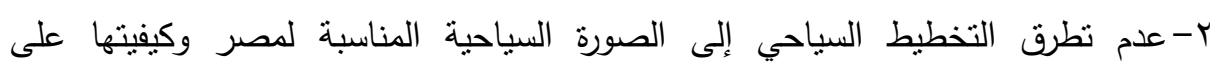
المستوي الدولي والمحلي فليس هناك أي جذب بين الطلب السياحي أو المستهدف.

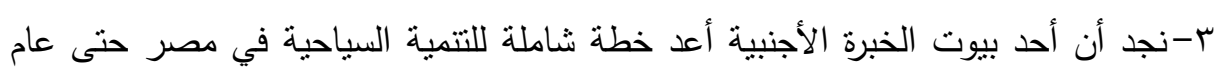

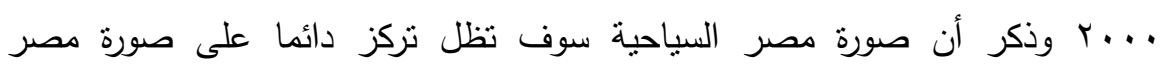
الفرعونية، بمعني النمط الثقافي الذي يعتد على مشاهدة الآثار التاريخية القديمة وأن فكرة

$$
\text { الحضارة مرتبطة بمصر . }
$$

- حيث مصر في المرنبة الثانية في مجال السياحة التقافية بالمقارنة ببعض الدول المنافسة

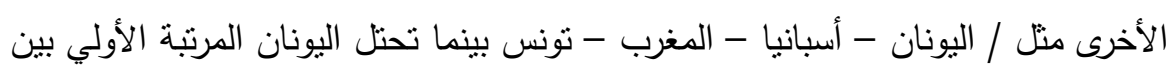

$$
\text { هذه الدول. }
$$

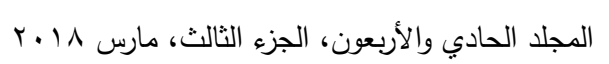


ع-ارتفاع مستوي أسعار الخدمات السياحية التي تقدم في مصر منها (وسائل النقل - الفنادق

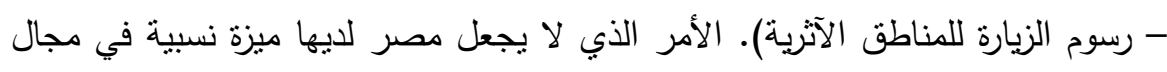

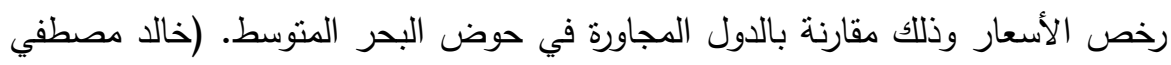

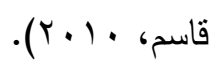

\section{هروضر الستواسة}

ا • يمكن لقطاع السياحة المصري أن يلعب دورا بارزا في دعم التتمية المستدامة.

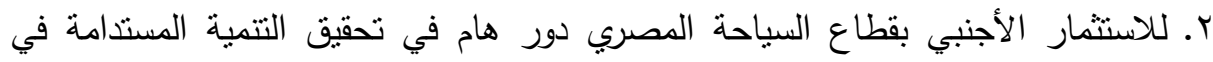

r. يمكن الاتجاه إلى التتمية المستدامة بواسطة الاقتصاد الأخضر والعمارة البيئية "

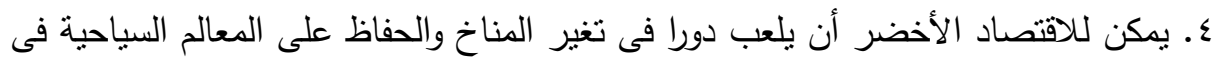

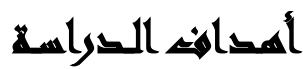

ا ـ التعرف على معوقات ومحددات النشاط السياحي في مصر وكيفية دعمه.

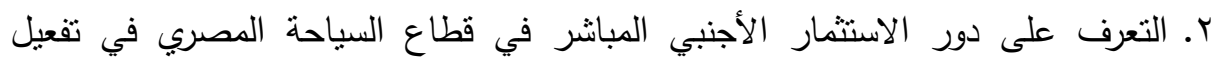

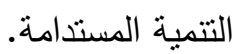
r. دراسة إمكانية تفعيل التتمية المستدامة في مصر من خلال القطاع السياحي. ع. دراسة الاقتصاد الاخضر ومدى تحقيقة فى مصر. 0. تحقيق نوعية حياة أفضل للسكان. 7. - الحفاظ علي البيئة واحترامها. V V. نرشيد الاستخدام العقلاني للموارد. A. تعزيز وعي السكان بالمشكلات البيئية القائمة. 9 . ربط التكنولوجيا الحديثة بأهداف المجتمع. • 1. إحداث تغيير مستمر ومناسب في حاجات وأولويات المجتمع. 
1 ا. تحقيق معدلات نمو عالية للاخل وعدالة توزيعه وتقليص التقاوت في الدداخيل. ومن الأهداف الاستراتيجية للتنمية المستدامة والتي لابد أن ترسمها الدول أمامها وتسعي توني لتحقيقها من خلال استراتيجية النتمية المستدامة التي تتبعها وهي: - تحقيق معدلات النمو ونوعية النمو. - توفير الحاجات الأساسية من عمل، غذاء، ماء طاقة، مرافق صحية وغيره.

\section{أdiand}

- تزايد أعداد الاتفاقيات الثنائية التي تشجع الاستثمارات بين الدول بعضها البعض.

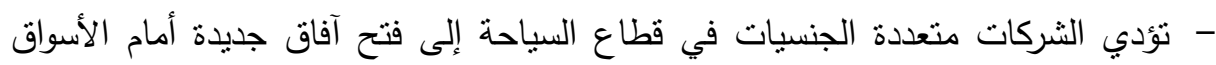
والمنتجات المحلية والدخل المصري. - الفوائد التي تعود للبلاد عندما تفعل التتمية المستدامة في الاستثمار الأجنبي المباشر في قطاع السياحة في مصر. - تقيم كفاءة الاستثمار الأجنبي المباشر في قطاع السياحة في مصر ومساهمته في تحقيق

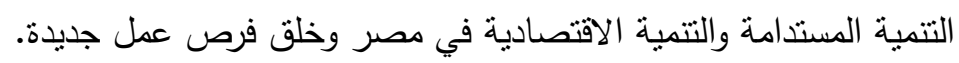

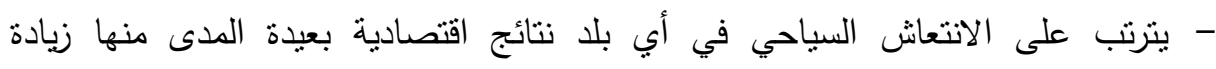
الاستثمارات مما يساعد على دفع عجلة التتمية الاقتصادية.

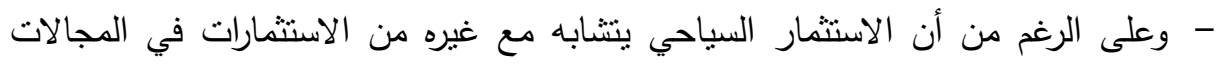
الأخرى غير السياحية وذلك من ناحية رغبة المستثمرين في تعظيم الربح إلا أنه يتميز

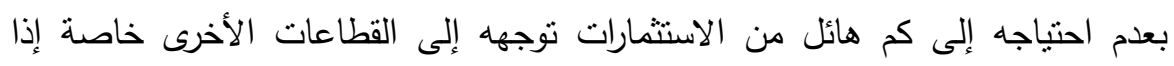

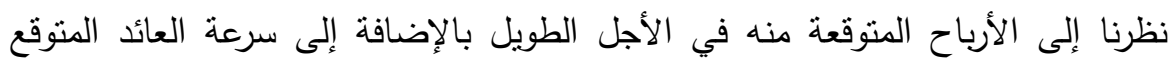

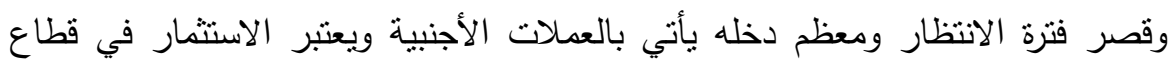

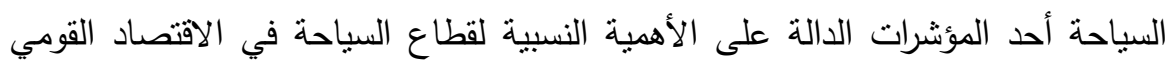
ومدى أهمية تطبيق التتمية المستدامة ومدى الإنتاج الذي يعم على معظم الدول من الأمينة الناحية البيئية والاقتصادية. 
- من هنا فإننا سنحاول في دراستتا آن نتطرق للاستثمارات السياحية في مصر والوزن النسبي للاستثمار الأجنبي فيها ودور تلإنك الاستمارات في تحقيق التنمية المستدامة في

\section{أثر الاستثمار السباحي على الاقتصاد القومي:}

ا ـ تشيط الدورة الاقتصادية بهذا الإنفاق الاستثماري.

r. إعادة توزيع الدخل على المناطق السياحية المختلفة والتي قد تكون محرومة من النشاط الاطفاط

$$
\text { الاستثماري، ومن ثم تحقيق التوازن الإقليمي. }
$$

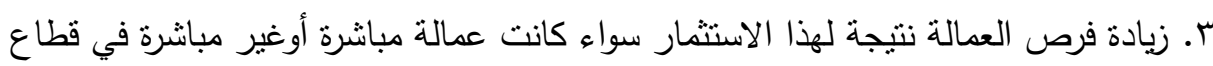
التشييد والصناعات الخشبية والأنشطة الأخرى المتصلة بإنشاء المشروعات السياحية.

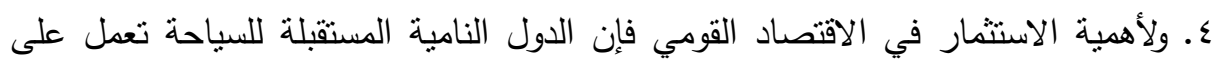
تحقيق مناخ استثماري مستقر سواء بالنسبة للاستثمارات الوطنية أوالأجنبية. ويالنسبة للتنمية المستدامة: يمكن التعرف على التتمية المستدامة من خلال نوضيح

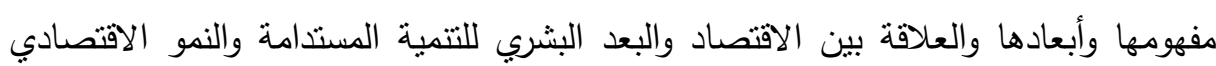
ومؤشرات قياس التتمية المستدامة. تعريف التنمية المستدامـة: هي التتمية التي تلبي احتباجات الأجيال الحاضرة دون المساس أوالأضرار باحتباجات الأجيال القادمة والعمل على تحقيق العدالة فيما بين الأجيال وداخل الجيل الواحد ويوجد كثير من تعريفات للتنمية المستدامة. عرفت التتمية المستدامة Sustainable Development بناءً علي تقرير مستقبلنا المشرك الصادر عن اللجنة العالمية للتمية والبيئة عام 9Av 19، والذي جمع بين المحاور والركائز الاساسية للتتمية المستدامة، والمتمثلة في الاحتباجات الاقتصادية والاجتماعية

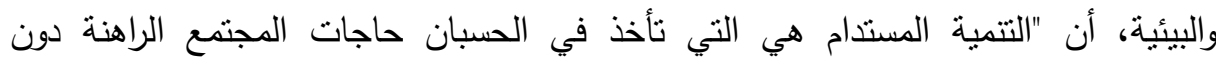
المساس بحقوق الاجيال المقبلة في الوفاء باحتياجاتهم" (اللجنة العالمية للبيئة والتتمية، 
كما عرفت التتمية المتواصلة: "أنها التتمية الحقيقية ذات القدرة علي الاستقرار، والاستمرار، والتواصل من منظور استخدامها للموارد الطبيعية، والتي يمكن ان تحدث من

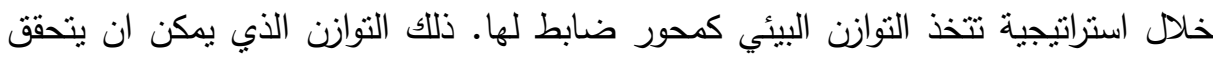
من خلال الإطار الاجتماعي البيئي الذي يهدف إلي رفع مستوي معيشة الافراد من خلال النظم السياسية، والاقتصادية، والاجتماعية، والثقافية التي تحافظ علي تكامل الإطار البيئي من خلال استخدام الموارد البيئية، وتعمل علي نتميتها في نفس الوقت. (وفاء أحمد عبد الله،

وعلي ضوء هذا التعريف نجد أن التتمية المستدامة تتطلق من استراتيجية قائمة، ومبنية

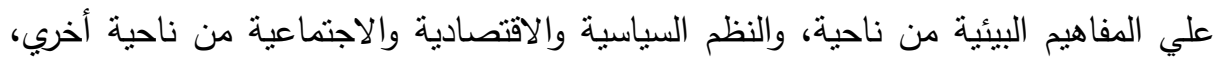

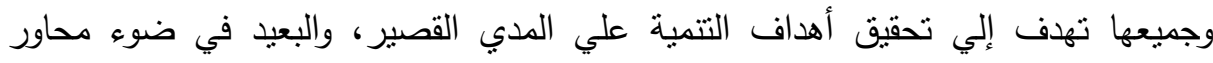

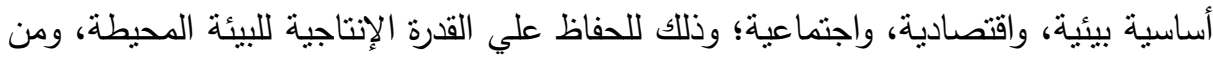
أجل سلامة الحياة الطبيعية، والتتوع الحيوي، وإنتاج الثروات المتجددة، والحفاظ علي الثروات

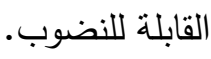

تعريف الفاو للتتمية المستدامة والتي تنتته في عام 1919 كما يلي: "إن التتمية المستدامة هي إدارة وحماية قاعدة الموارد الطبيعية، وتوجيه التغير التقني والمؤسسي بطريقة تضمن تحقيق، واستمرار إرضاء الحاجات البشرية للأجيال الحالية والمستقبلية. إن تلك التتمية واندية المستدامة (خاصة في الزراعة والغابات والمصادر السمكية) تحمي الارض والمياه، والمصادر المبرد

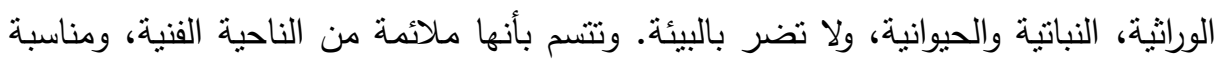

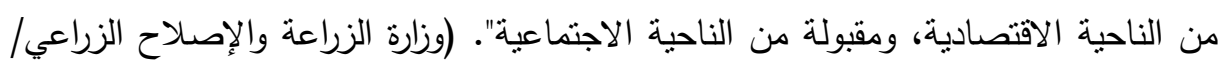
المركز الوطني للسياسات الزراعية مواد تدريبية، الاقتصاد البيئي والتتمية المستدامة، بـ . .ب).

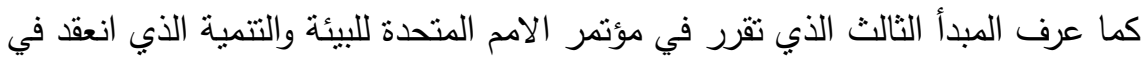

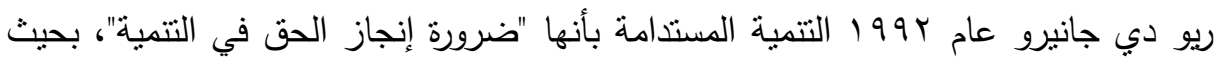

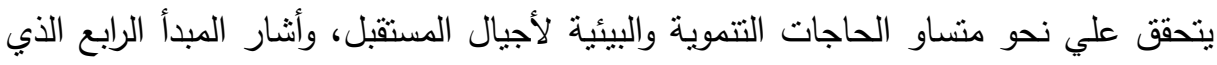
أقره المؤتمر إلي أنه "لكي تتحقق التتمية المستدامة ينبغي أن تمنل الحماية للبيئة جزءاً لا يتجزأ

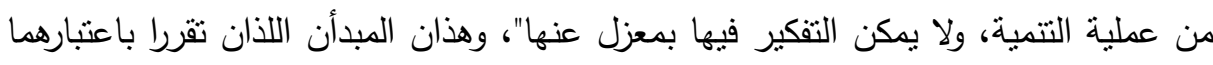

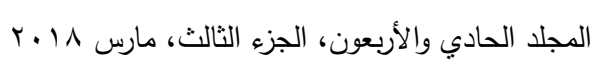


جزءاً من جدول أعمال مؤتمر الامم المتحدة الحادي والعشرين، ينطويان علي بعض الدلالات

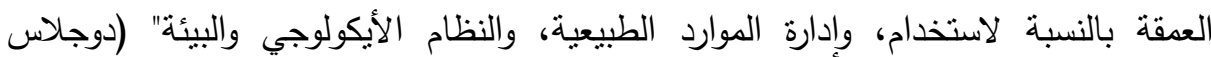
ماشسيث، مبادئ التمية المستدامة، ترجمة بهاء شاهين، . . . ب).

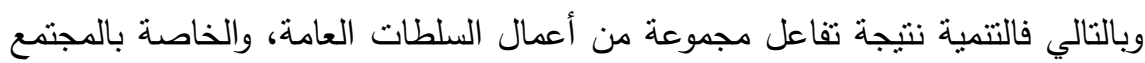
من أجل تلبية الحاجات الأساسية، والصحية للإنسان، وتتظيم تتمية اقتصادية مفيدة، وتحقيق انسجام اجتماعي في المجتمع، وتوازن بيئي بغض النظر عن الاختلافات الثقافية والدينية، وغيرها مع شرط مراعاة حق مستقبل الاجيال القادمة.

(Parris., T. M. \& Kutes, R. W.: 2003)

وذلك يتفق مع تعريف Berbier للتتمية المستدامة وهو"أنها النشاط الاقتصادي الذي يؤدي إلي الارتقاء بالرفاهية الاجتماعية بأكبر قدر ممكن من الحرص علي الموارد الطبيعية المتاحة، وبأقل قدر ممكن من الاساءة إلي البيئة". (Berbier, E.: 1987) والتتمية المستدامة تعني عملية فاعلة للتغيير يقوم بها المجتمع بأكمله، ويتتاغم فيها استغلال الموارد، وتوجهات الاستثمار، والجوانب التكنولوجية في التتمية، وكذلك تغيير بهابه المؤسسات وتعزيز كل من إمكانيات الحاضر والمستقبل من أجل الوفاء باحتياجات الانسان،

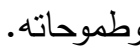
ونلاحظ بعض الاختلافات حول مفهوم التتمية المستدامة، ويمكن إرجاعها بشكل عام إلي أن موضوع الاستدامة تم تتاوله علي مستويات مختلفة. فالاستدامة علي المستوي الوطني

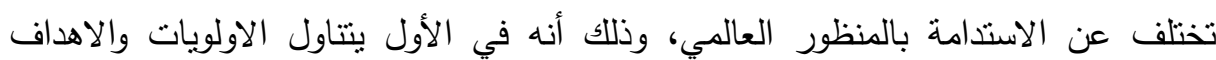

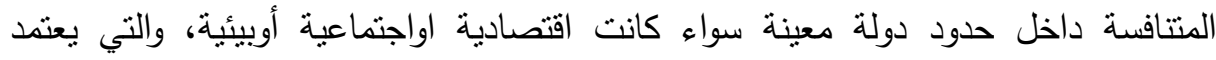

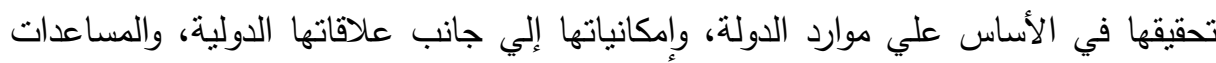
التي تقدم إليها. أما المنظور العالمي فيتم التركيز علي القضايا الأيكولوجية الكونية متلك:

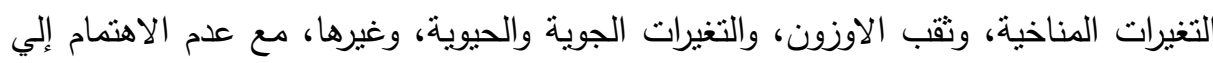

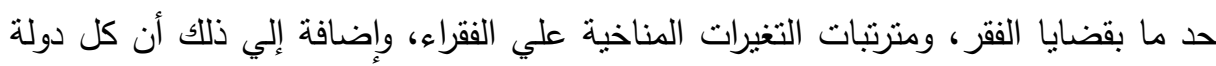
تهنم بصورة أساسية بتحقيق مصالحها الخاصة، وربط ذلك بالمنح، والمعونات من أجل تحقيق إنيق 
مكاسب ذاتية خفية، وسافرة تهدف إلي تحقيق الاستدامة في داخل بلدانها. (محد زكي علي

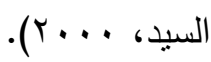

إن قضايا البطالة والفقر، وسوء توزيع الدخل، والحروب يمكن أن تؤدي إلي مشاكل

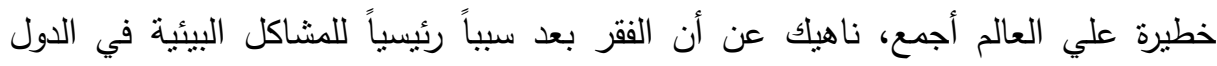
النامية، وهنا تكون الحاجة ملحة إلي معالجة الفقر، واجتثاثه من كل دول العالم، حفاظاً علي العي

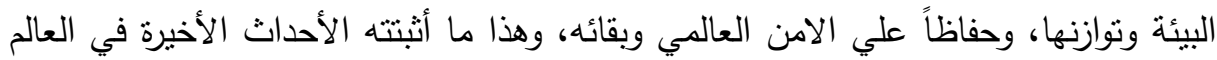

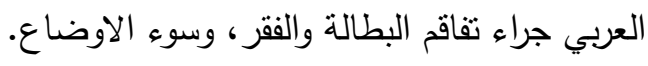
ولتحقيق التتمية المستدامة داخل البلاد لابد من نوافر ثلاثة أبعاد أساسية هي:

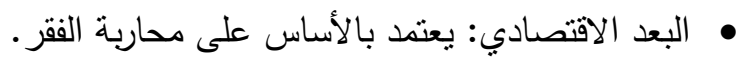

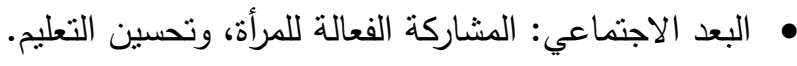
• • • البعد البيئي: الحفاظ على البيئة من التدهور •

ويجب على الثركات متعددة الجنسيات بجميع صورها الحفاظ على البيئة في ظل وجود البئل التتمية المستدامة وتدعيمها في جميع البلاد وذلك من خلال إطار للإستراتيجية الإنتاجية العالمية الموحدة بجميع القوانين والثروط والالتزام بها.

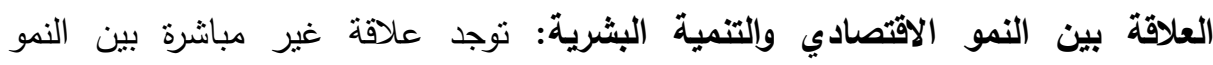

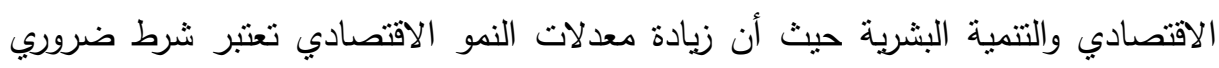
وليس كافي لتحقيق التتمية البشرية ، فزيادة معدلات النمو الاقتصادي ضرورية لنية لكي ينت

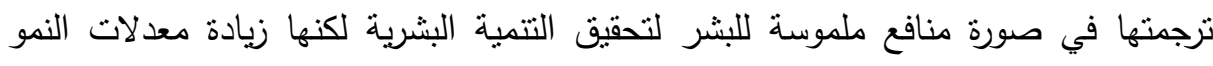
الاقتصادي في حد ذاتها لا توفر ضماناً لتحقيق التتمية البشرية والدليل على ذلك فئه أن هنآك

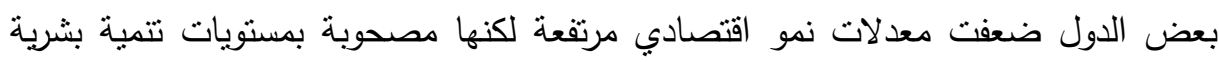

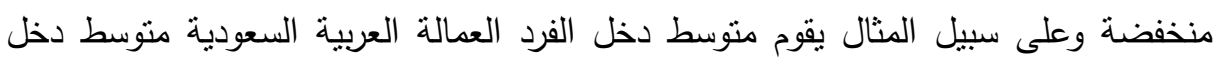
الفرد في تايلاند ولكنهما يتشابهان من حيث مستوى التتمية البشرية وهوما له أهمية السياسات المتبعة لترجمة النموالاقتصادي في صورة تحسن أوضاع التنمية البشرية. 
مؤثشرات قياس التنمية المستدامـة: تساعد المؤشرات على زيادة القدرة على إنخاذ

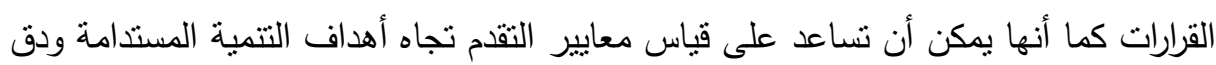
ناقوس الخطر في الوقت المناسب لمنع الأضرار الاقتصادية والاجتماعية أو البيئية.

\section{وتوجــ عدة مئشيرات للتنمية المستـامـة:}

مؤشعات الادخار الحقيقي: هو صافي الادخار المعدل: يقدم مؤشرًا أوسع بكثير للاستدامة

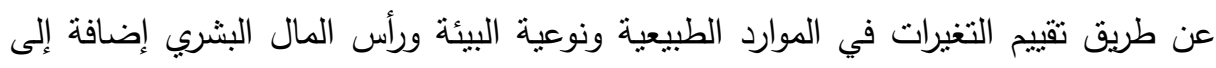

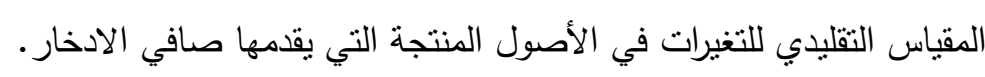

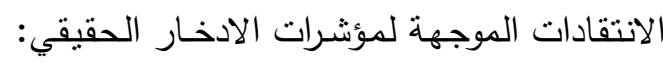

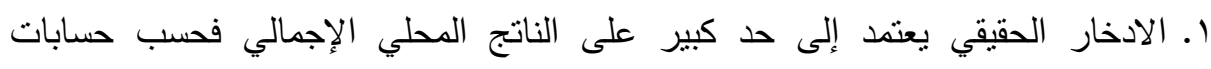

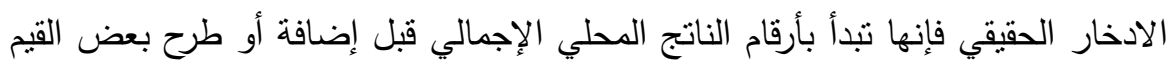
وهي بذلك تميل إلى زيادة الناتج المحلي الإجمالي الحقيقي أو النمو الاقتصادي كمؤشر الإن أساسي للتقدم تجاه التتمية المستدامة.

r. هناك بعض الأصول الهامة حذفت من التحليل لأسباب منهجية وعملية مما يعني أنه يجب نوخي الحذر في تفسير معدلات الإدخار الحقيقي الإيجابية.

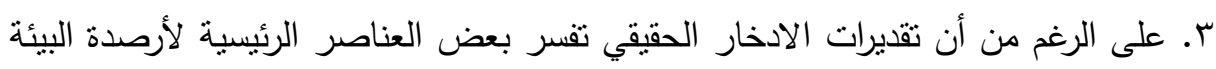

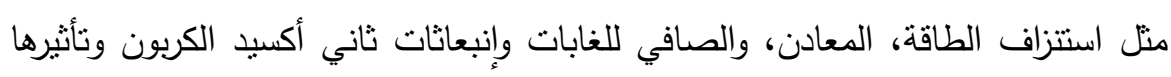

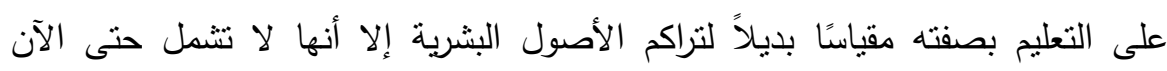

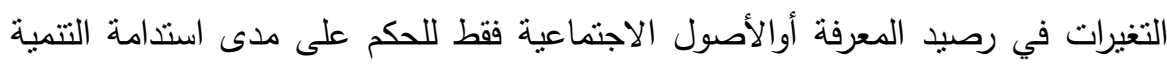
المستدامة.

ع. مقياس الادخار الحقيقي يقوم على مفهوم "ضعف الاستدامة" التي يقوم على الاستعاضة

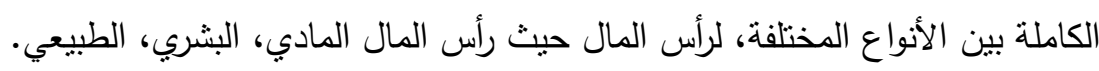


فإن قوة الاستدامة نقترح الحفاظ على سلامة رأس المال البيئي على مر الزمن منل سلامة الأنظمة الإيكولوجية باستمرار وضعف الاستدامة فإن الإحلال من الناحية الاقتصادية

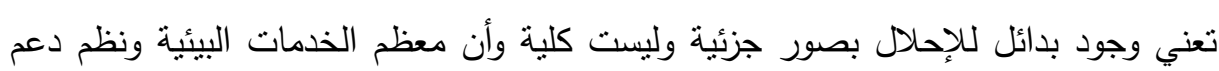
الحياة وخدمات الموارد الطبيعية ليس لها بدائل. المؤثرلت الرئيسية والفرعية لقياس التنمية المستدامية:_تتناول المؤشرات التي أعدتها الأمم المتحدة من أجل قياس ورصد التتمية المستدامة ومدى تحقيقها في كل دورة.

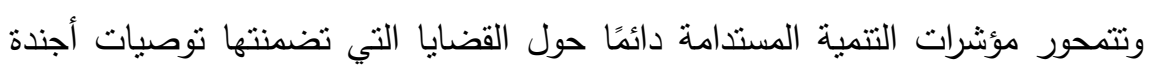
القرن الحادي والعشرين وهي نتكيل إطار العمل البيئي في العالم وقد تحددت في القضايا التالية: المساواة الاجتماعية، الصحة العامة، التعليم، الفئات الاجتماعية، أنماط الإنتاج

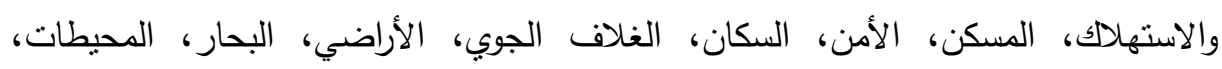

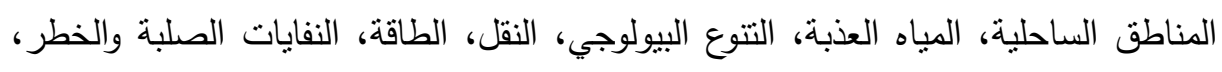

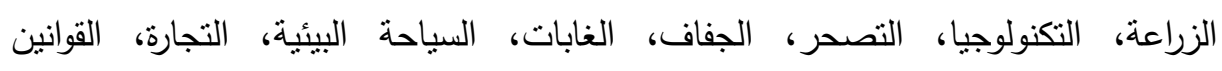
والتشريعات والأطر المؤسسية.

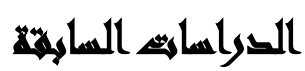

اهتمت العديد من الدراسات السابقة بدراسة أثر التتمية السياحية على الوضع البيئى

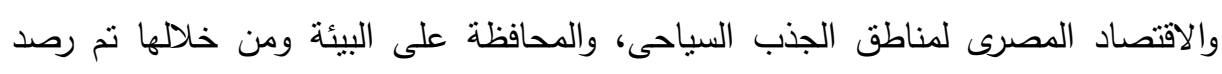

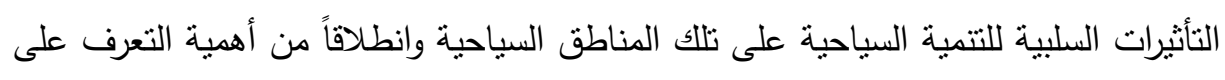

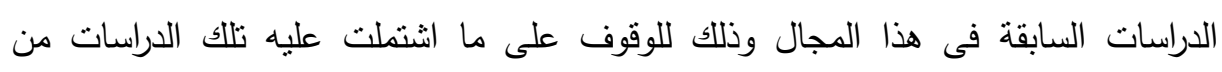

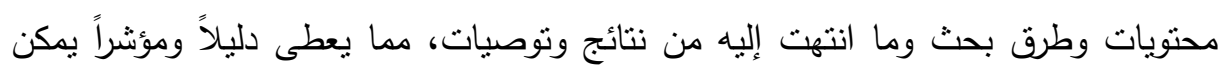
الاهتداء به فى تلك الدراسة.

فى دراسة تامر عبد اله البسطويسي "تقييم الحمل البيئي للتخطيط الاستراتيجي لأعمال

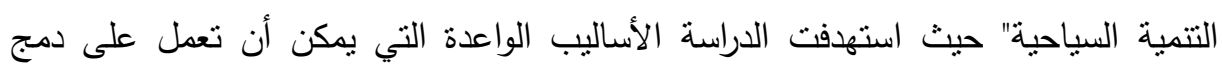

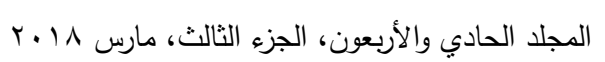


الاعتبارات البيئية واعتبارات الاستدامة في صلب عملية الاقتصاد المصرى سياسات التتمية واتخاذ القرار بها.

فى دراسة وفاء فتحى عبد العظيم محمد "دور السياحة العلاجية فى تتمية قطاع السياحة

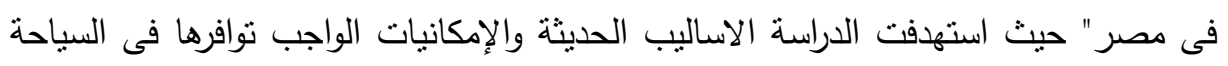
العلاجية للتوافق مع الاستدامة والتتمية السياحية.

فى دراسة زينب فؤاد عبد اللطيف ابراهيم "آليات تفعيل نطبيق التتمية المستدامة فى ولى الاقتصاد المصري" حيث استهدفت الدراسة مدى فاعلية وتأثير نطبيق الاليات المستخدمة والحديثة والمقترحة فى الاقتصاد ومدى تأثيرها فى تطبيق الاستدامة وتأثنرها على البيئة .

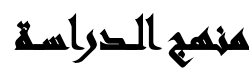

تم استخدام المنهج التحليلى الذى اعنمد على الكتب والدوريات والنشرات والرسائل لمعرفة مدى اعتبار المشكلات البيئية عامل مهم للسياحة ومدى مساهمتها في تحقيق التنمية اعلية المستدامة ومدى مساعدة السياسات الاقتصادية المتتوعة لبلوغ ذلك الهدف ومن ثم تعظيه

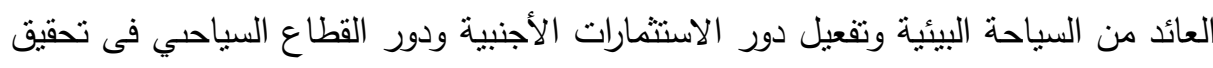

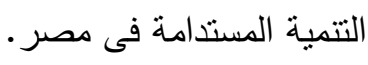

\section{هصوض التواسم}

الزمنية: يمند النطاق الزمني للاراسة منذ منتصف التسعينات وحتى عام 10 . r.

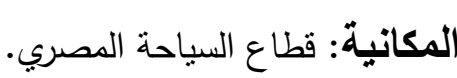

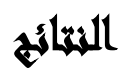

ا. التحرك نحو الإقتصاد الأخضر يكون له القدرة على تحقيق التتمية المستدامة والقضاء

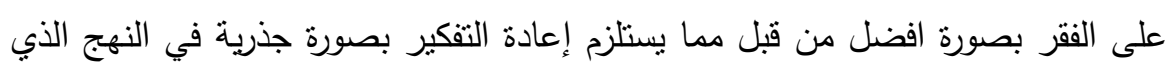
نتبعه في الإقتصاد كما اتفقت مع دراسة وفاء فتحى عبد العظيم محمد. 
r. الاقتصاد الأخضر يدعم النمو والدخل وفرص العمل على المدى الطويل (.r.r. وما بعدها) فإن الانتقال إلى الاقتصاد الأخضر سوف يتفوق على العمل المعتاد من خلال

$$
\text { التدابير التقليدية الأكثر شمولاً. }
$$

r. تعتبر السياحة من أهم مكونات الاقتصاد القومي فهي من أهم مصادر الإيرادات في ميزان الددفوعات كصادرات خدمية وتساهم بفاعلية في زيادة الناتج المحليكما اتفقت النتائج مع الئردي

$$
\text { دراسة زينب فؤاد عبد اللطيف ابراهيم. }
$$

ع. السياحة الخضراء صناعة مستديمة لا تضر بالبيئة الطبيعية وهي منتجة وفعالة ذات تأثثر إيجابي كبير على جميع جوانب الاقتصاد البيئي وأداة لتحقيق أهداف التتمية المستدامة كما

$$
\text { أن للسياحة دوراً هاماً في هذه الإيجابيات الاقتصادية والبيئية. }
$$

ه. تتطلب التتمية السياحية المستدامة التتاسق والتكامل بين الاستفادة من الموارد البيئية والتطور التكنولوجي وتدفق الاستثمارات حتى يتحقق هدف ربط الحاضر بالمستقبل لتلبية الرغبات المختلفة ولوتوافرت البنية الأساسية التى يعتمد عليها الاستثمار ورأس المال

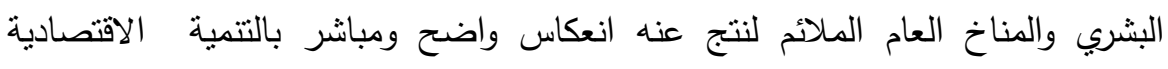
وبالتالي التتمية المستدامة والاستثمارات الأجنبية الضخمة من أثر كبير على الاقتصاد

$$
\text { المصري واتفقت نتائج هذه الدراسة مع دراسة تامر عبد الله البسطويس. }
$$

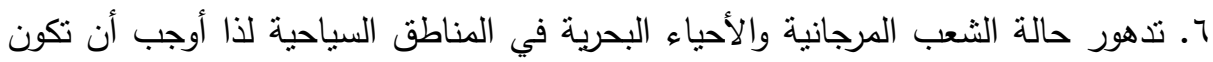

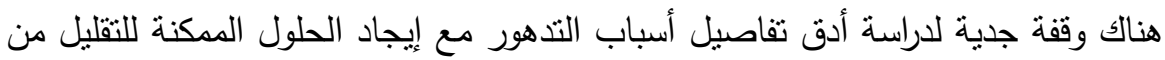

$$
\text { التأثثرات السالبة للتتمية السياحية. }
$$

V. انعدام الوعي البيئي يساهم في تعديق المشاكل البيئية مما يؤكد ضرورة نطبيق الالتزامات الخضراء والتي تؤدي لنشر ثقافة الالتزام الوقائي لتلافي النلوث قبل حدوثه، فهنالك موارد

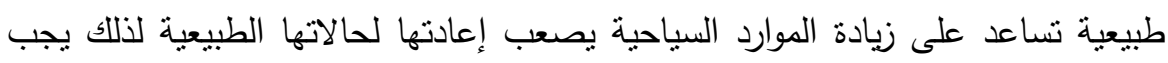
التوعي البيئي لتحقيق التنمية المستدامة وزيادتها. 
مجلة العلوم البيئية

معهد الدراسات والبحوث البيئية - جامعة عين شمس ليه

\section{المئوسياتي}

ا ـ ضرورة تطبيق السياحة الخضراء فهي ذات تأثير إيجابي كبير على جميع جوانب الاقتصاد البيئي والتتمية المستدامة. r. الاتجاه نحو السياحة البيئية بصورة أكبر بإنشاء فنادق على الطراز البيئي وتوفير حتى نشجع شركات السياحة بتتظيم رحلات السياحة البيئية. r. إزالة المعوقات البيئية من نقص الإمكانيات اللازمة لنطوير المناطق البيئية وعدم نوافر

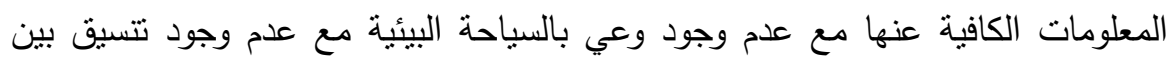
الأجزة المختلفة مما ينعكس على الطلب السياحي والزيادة في الإيرادات السياحية. ع. التعاون مع كلا من جهاز شئون البيئة وهيئة التتمية السياحية والمحافظة في الالتزام بتتفيذ الإئي وتطبيق قوانين حماية البيئة وحماية المحمبات الطبيعية ومراعاة البيئة المنظمة للمشروعات السياحية الجديد للوصول إلى التتمية السياحية المستدامة والحفاظ على الموارد السياحية

$$
\text { من التدهور البيئي التى تؤدي الي انعدامها. }
$$

ه. العمل على القضاء على الفقر من خلال التحرك نحوالاقتصاد الأخضر لما لديه من قدرة لهدرة على تحقيق المستدامة ودعم النمووالدخل والمزيد من فرص العمل على المدى الطويل.

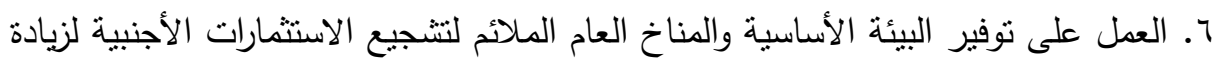

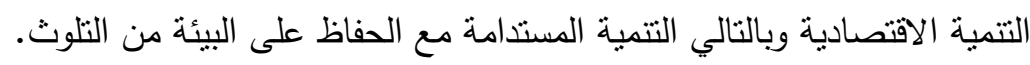

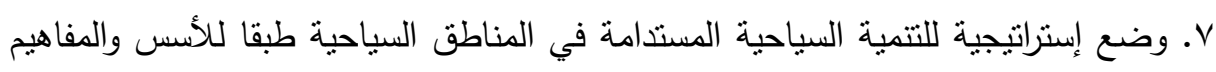
والنظريات البيئية التي تهدف إلى تحقيق هذه الاستدامة في ظل التحولات العلمية المعاصرة. ^. إنشاء المزيد من الفنادق البيئية نظرا لطبيعية السائحين المترددين على المناطق السياحية منل البحر الأحمر واهتماههم في المقام الأول بالسياحة البيئية.

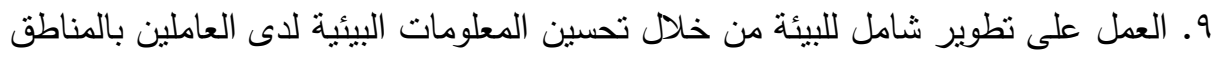
السياحية التي تطرأ عليها تغيرات وأضرار وخسائر بيئية مما بساهم في إعداد مؤشرات النتمية المستدامة واستخدام أفضل للموارد البيئية. 
• 1. وضع بعض الإجراءات اللازمة التي تساعد على جعل الأنشطة السياحية ذات جدوى اقتصادية تساعد في تحقيق التتمية المستدامة للبيئة السياحية. 11. التوجه إلى المناطق السياحية لإعطاء فرص عمل أفضل وزيادة في الدخل والتوعية البيئية اللازمة التي تساعد في تحقيق الاستدامة داخل البلد.

\section{zall}

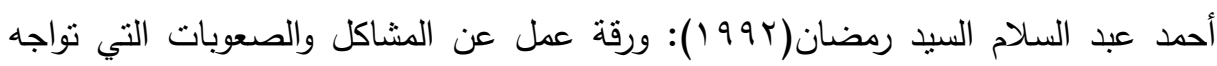
التتمية البشرية في الوطن العربي، المؤتمر الخامس عشر ، وامن جامعة المنصورة،

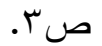

أمارتيا سن(· ( ץ): ترجمة شوقي جلال، التتمية حرية، المركز القومي للترمة، مصر، ص

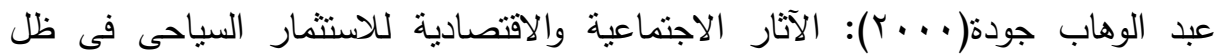

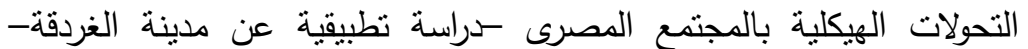
رسالة دكتوراه، آداب عين شمس، بالنع القاهرة

ف. دوجلاس ماشسيت: مبادئ التتمية المستدامة، ترجمة بهاء شاهين، الدار الدولية

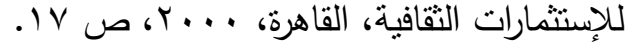

اللجنة العالمية للبيئة والتتمية(9AvV (1): مستقبلنا المشترك، ترجمة محمد كامل عارف، مرجع

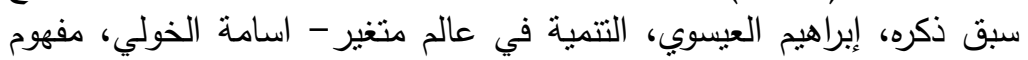

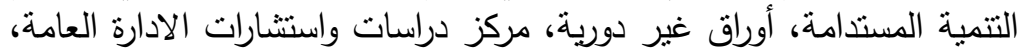

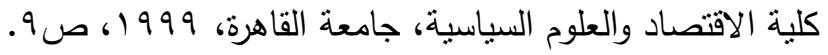

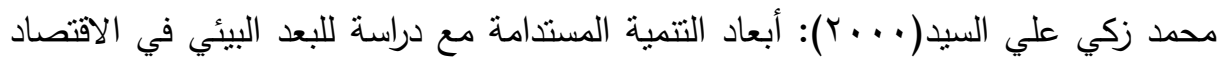

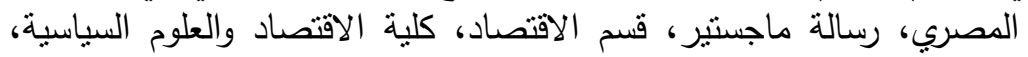

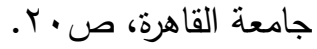

وزارة الزراعة والإصلاح الزراعي/ المركز الوطني للسياسات الزراعية مواد تدريبية، الاقتصاد

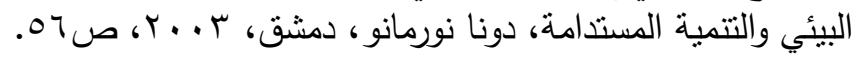

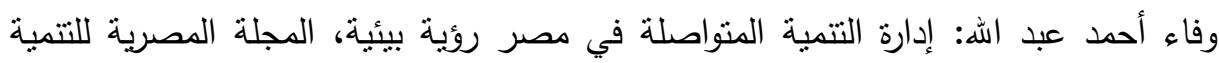

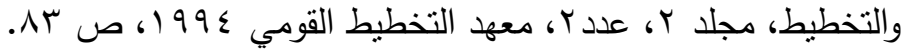

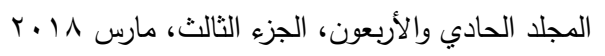




$$
\text { معهد الدراسات والبحوث البيئة - جامعة عين شمس البيئة }
$$

Parris, T. M. \& Kutes, R. W. (2003): "Characterizing and Measuring Sustainable Development, Annual Review of Environment and Resources, Vol. 28, p. 559.

Berbier, E. (1987): The concept of Sustainable Economic Development, Environmental Conservation, Vol 14, No.2, p. 91.

\title{
THE ROLE OF THE TOURISM SECTOR IN ACTIVATING SUSTAINABLE DEVELOPMENT
}

\section{[16]}

\author{
Farahat, Abeer ${ }^{(1)}$; Gohar, K. M. ${ }^{(1)}$; Hasanin, M. M. ${ }^{(2)}$ \\ and Ali, Doaa, M.
}

1) Faculty of Commerce, Ain Shams University 2) Tourism Development Agency

\begin{abstract}
This research drives at examining tourism and sustainable development and their impact on important productive sectors in lots of states' economics either the developed or the developing. Tourism is an economic activity characterized by producing foreign currency for states used for pushing development wheels. It also drives at identifing the obstacles and determinants of tourist activity in Egypt and the role of foreign direct investment in Egyptian tourism sector for activating sustainable development and setting standards for optimal use of resources without affecting them passively.

Tourism in Egypt is still a highly capable resource for development for the multiple potentialities and potentials the state owns for tourism that meet the global demands and terms such as archeological tourism, cultural tourism, religious tourism, treatment tourism, businessmen tourism, sports and marine tourism. This type of investment definitely increases work opportunities directly or indirectly as tourist states work on achieving stability climate viable for investment. Nevertheless, environmental problems represent a dismissible factor for tourists since
\end{abstract}

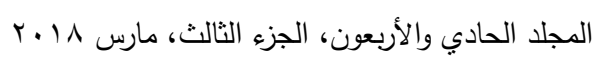


عبير فرحات وآخرون

the unconcern in treating such problems affects the state's exerted efforts to develop and refresh this sector, affecting also national or international investment. Economic policies are considered a significant effective factor in fulfilling the tourist investment job affecting also its activity. The study also examines the green economy and its applicability in Egypt, rationalizing utilization of resources and reinforces inhabitants' awareness of environmental problems.

Study results indicate that moving towards green economic can achieve sustainable development and eliminating poorness as it increases investment, labor opportunities, sustain industry and development which are all targets of sustainable tourism.

Recommendation indicate to the necessity of setting policies and strategies for sustainable tourist development, providing the infrastructure and general appropriate climate for foreign investment to increase the economic growth and so the sustainable development in one hand and conserving environment from pollution on the other hand. 